\title{
Эволюция палинокомплексов отложений аллювиальной формации Байкальской рифтовой зоны в неогене
}

\author{
@2020 Т. Ф. Трегуб ${ }^{1}$, М. А. Волков ${ }^{1 凶}$, А. И. Хасан ${ }^{2,3}$, А. Аль Хамуд ${ }^{2,4}$ \\ ${ }^{1}$ Воронежский государственный университет, \\ Университетская пл., 1, 394018, Воронеж, Российская Федерация \\ ${ }^{2}$ Иркутский государственный университет, \\ Карла Маркса, 1, 664003, Иркутск, Российская Федерация \\ ${ }^{3}$ Университет Аль-Баас, г. Хомс, Сирия \\ ${ }^{4}$ Университет Аль-Фурат, Дейр Эз-Зор, Сирия
}

\begin{abstract}
Аннотация
Введение: В настоящее время остается не решенной проблема выделения стратонов в осадочных отложениях неогенового периода территории Байкальской рифтовой зоны. Для решения этого вопроса необходимо провести сопоставление результатов палинологических исследований отложений позднего кайнозоя Восточных Саян и южного побережья озера Байкал и их систематизацию в хронологическом ряду палеогена-неогена.

Методика: Все образцы обрабатывались по сепарационному методу Гричука, который включает: обработку $10 \%$ соляной кислотой $(\mathrm{HCl})$, щёлочью $(\mathrm{NaOH})$, плавиковой кислотой $(\mathrm{HF})$ и тяжёлой жидкостью $\left(\mathrm{KJ}+\mathrm{CdJ}+\mathrm{H}_{2} \mathrm{O}\right)$. После обогащения мацерат просматривался под микроскопом с увеличение х400-х600. Принадлежность спор и пыльцы к секциям, родам и видам определялась по признакам морфологического строения экзины, энтины, апертурного аппарата, пор и наличия борозд.

Результаты и обсуждение: Описанный палинологический материал отложений озерноаллювиальной формации южного побережья Байкала и осадочных образований, перекрытых базальтами тиссинской серии на территории Восточных Саян, сопоставлен с данными стратотипических разрезов прилегающих регионов. Это позволило обосновать соответствие полученных данных стратиграфическим рубежам региональной схемы неогена. В эоцене в общем составе пыльцы преобладают покрытосеменные. Последний этап олигоцен характеризуется преобладанием голосеменных. В нижнем миоцене также преобладает пыльца голосеменных, но в отличие от олигоцена увеличивается количество пыльцы покрытосеменных. Для среднего миоцена характерно богатое видовое разнообразие пыльцы как покрытосеменных, так и голосеменных пород. В плиоцене ведущее значение занимает пыльца голосеменных.

Заключение: Детальный анализ состава палинокомплексов позволил впервые обозначить наличие на данной территории отложений палеогеновой системы и выстроить в хронологическом ряду спорово-пыльцевые комплексы неогена. На основе палинологических исследований в Байкальской рифтовой зоне, определены хронологические рубежи базальтовых покровов тиссинской серии, в рамках миоцена-нижнего плиоцена. А также возрастные границы толщ и свит озерно-аллювиальной формации южного побережья Байкала в рамках верхнего эоцена-нижнего плиоцена.

Ключевые слова: Байкальская рифтовая зона, палинологические комплексы, стратиграфия, неогеновая система.
\end{abstract}

\footnotetext{
Волков Максим Андреевич, E-mail: 1994vomaan@mail.ru
} 
Для циитирования: Трегуб Т. Ф., Волков М. А., Хасан А. И., Хамуд А. Аль' Эволюция состава палинокомплексов для отложений аллювиальной формации Байкальской рифтовой зоны в неогене // Вестник Воронежского государственного университета. Серия: Геология. 2020. №1. С. 39-50. DOI: https://doi.org/10. 17308/geology.2020.1/2512

Источник финансирования: Исследование выполнено при финансовой поддержке гранта РФФИ №1835-00417 мол_а.

\section{Введение}

Проблема выделения стратонов в осадочных отложениях неогенового периода для территории Байкальской рифтовой зоны до настоящего времени до конца не решена. С целью комплексного изучения разрезов неогена данной территории в течение последних лет в биостратиграфической лаборатории Воронежского государственного университета проводились палинологические исследования осадочных отложений ряда обнажений и скважин. В ходе работ были изучены спорово-пыльцевые комплексы из отложений восьми разрезов на территории Восточного Саяна и в долинах рек Баргузин и Мишиха. Обоснование хронологической приуроченности палинокомплексов проводилось на основе сопоставления с палинологическими материалами стратотипических разрезов прилегающих регионов: Восточно-Сибирского, Северо-Восточного и Восточно-Азиатского $[1,2,3]$. Полученные результаты позволили обосновать возраст отложений выделяемых толщ и свит в соответствии с региональной стратиграфической схемой неогена.

\section{Методика}

Для получения палинологических материалов на территории южного побережья озера Байкал анализировались озерно-аллювиальные отложения двух обнажений северной и южной Мишихи и отложения разреза скважины 545 в речной долине Баргузин.

Краткие сведения о литологическом составе изучаемых отложений позволили использовать эти материалы для построения разрезов и спорово-пыльцевых диаграмм в соответствии с составом палинокомплексов с целью обоснования хронологических рубежей накопления отложений дотонхойской толщи, танхойской и аносовской свит [4].

В пределах Восточных Саян изучались осадочные отложения, перекрытые базальтовыми покровами тиссинской серии, которая объединяет три свиты: сорокскую, хирписинскую и хирбэсинскую. Валидные спорово-пыльцевые комплексы выделены из отложений пяти разрезов (обнажения 128, 123, 1137 и 5029-две расчистки). Богатый палинологический материал обеспечил детализацию стратиграфических границ, выделяемых свит тиссинской серии [5] (рис. 1).

Состав палинологических комплексов, выделенных из отложений вышеописанных разрезов, представлен в графическом выражении на споровопыльцевых диаграммах. Анализ изменений общего состава и вариаций отдельных компонентов позволил выделить на спорово-пыльцевых диаграммах палинологические зоны и подзоны, что в свою очередь обеспечило возможность выстроить палинологические данные в хронологическом ряду стратиграфической схемы неогеновой системы.

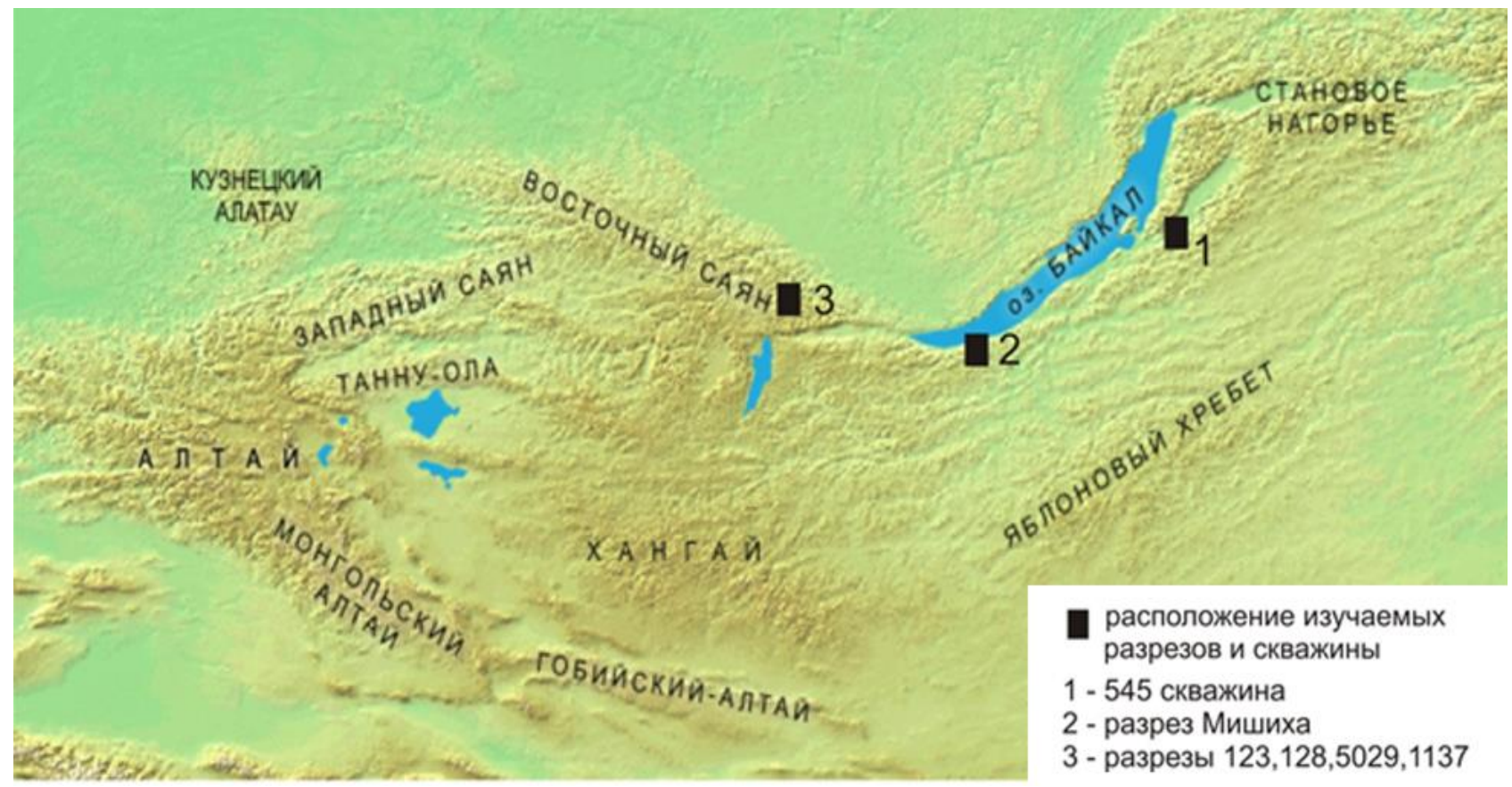

Рис. 1. Местоположение изучаемых объектов.

[Fig. 1. Location of the studied objects.] 


\section{Результаты и обсуждение}

Отложения северной и южной частей разреза Мишиха геологами Иркутского государственного университета первоначально рассматривались в пакетах последовательного накопления. Полученные палинологические материалы выявили их сложное геологическое строение. Краевые участки обнажения северной части разреза содержали палинокомплексы более древнего возраста, нежели в его центральной части. Для детального обоснования подобного вывода были проанализированы дополнительные образцы в разрезе северной части. Эти материалы позволили обосновать существование в разрезах Мишиха синклинальной складки с наклонной осью.

На сводной диаграмме двух обнажений разреза Мишиха отражены изменения основного состава палинокомплексов и соотношения отдельных компонентов, что позволило выделить 3 палинозоны, которые отражают тренд формирования палинофлоры в течение накопления изучаемых осадков (рис. 2).

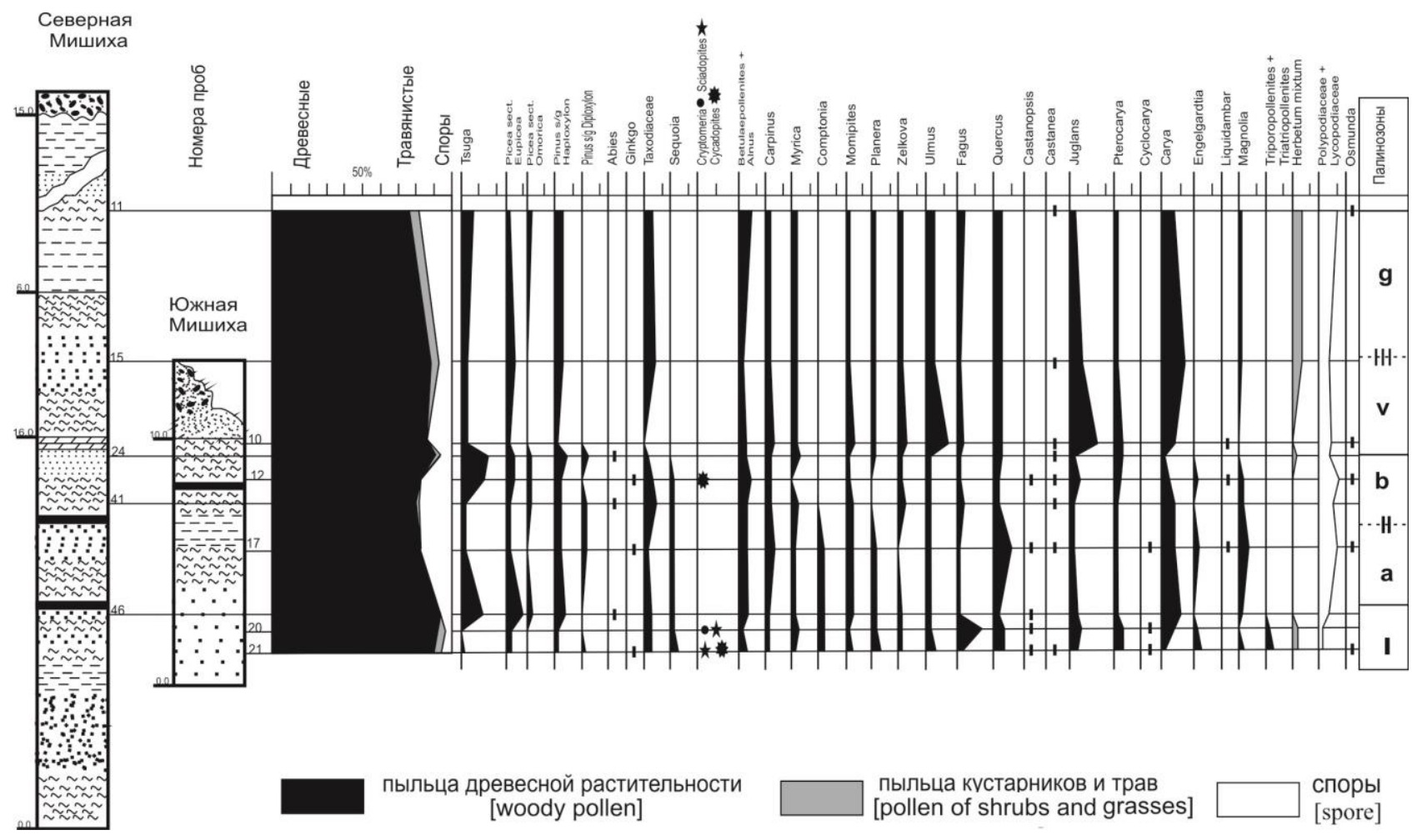

Рис. 2. Спорово-пыльцевая диаграмма разрезов северная и южная Мишиха.

[Fig. 2. Spore-pollen diagram of sections North and South Mishikha.]

Палинозона I обособлена на основании максимального количество пыльцы родов Fagus и Myrica, а также присутствия реликтов, относящихся к родам Cryptomeria и Sciadopites, характерных для палинофлор олигоцена. В целом палинокомплексы имеют большое видовое разнообразие, как пыльцы голосеменных растений, так и покрытосеменных. Элементы травянистой растительности представлены единичными зернами и к концу этапа исчезают из общего состава. Споры не многочисленны и отмечены в начале палинозоны. Представлены споровые растения семействами Polypodiaceae и Lycopodiaceae, роль которых возрастает к концу зоны.

Палинозона I обособлена на основании максимального количество пыльцы родов Fagus и Myrica, а также присутствия реликтов, относящихся к родам Cryptomeria и Sciadopites, характерных для палинофлор олигоцена. В целом палинокомплексы имеют большое видовое разнообразие, как пыльцы голосеменных растений, так и покрытосеменных. Элементы травянистой растительности представлены единичными зернами и к концу этапа исчезают из общего состава. Споры не многочисленны и отмечены в начале палинозоны. Представлены споровые растения семействами Polypodiaceae и Lycopodiacea, роль которых возрастает к концу зоны.

Состав комплексов I палинозоны позволил предварительно датировать данный интервал разреза эоцен-олигоценовым возрастом.

Во II палинозоне так же, как и в I в составе палинокомплексов наблюдается разнообразие состава пыльцы обеих групп палинофлор. Но в отличие от первой палинозоны здесь возрастает значение спор. Палинозона выделена, на основании максимальных значений пыльцы рода Tsuga, с видовым разнообразием, и семейства Taxodiaceae.

Состав палиноспектров позволил выделить в данной зоне две подзоны a и b. Подзона a обособлена на основании большого количества в нижней части пыльцы родов Tsuga и Picea, а в поздние этапы - пре- 
обладания пыльцы родов Quercus и Carya (с видами характерными для позднего олигоцена). Подзона b обозначена на основе максимальных значений пыльцы семейства Taxodiaceae и рода Tsuga с видовым разнообразием. Среди покрытосеменных пород доминирует пыльца семейства Juglandaceae (Juglans, Pterocarya, Carya). Палиноспектры подзоны а по данным состава можно отнести к нижнему миоцену, а спорово-пыльцевые спектры подзоны b рассматривать как переходные от нижнего к верхнему миоцену.

Палинозона III, в целом, характеризуется более бедным составом спор и пыльцы, как на видовом, так и на родовом уровнях по сравнению с I и II палинозонами. Кроме этого, в данной зоне было встречено гораздо большее количество пыльцы травянистых растений. На основе изменений в составе палинокомплексов были выделены две подзоны v и $\mathbf{g .}$

Подзона $\mathbf{v}$ характеризуется резким преобладанием пыльцы трех родов: Ulmus, Juglans, Carya на фоне снижения роли пыльцы голосеменных пород, вероятно, данный этап отразил одну из фаз миоценового оптимума. В подзоне $\mathbf{g}$ наблюдается снижение количества пыльцы родов Ulmus, Juglans, Carya. В целом количества пыльцы покрытосеменных и голосеменных имеют близкие значения. На данном этапе возрастает количество пыльцы травянистой растительности и спор. Состав палинокомплексов подзоны $\mathbf{g}$ можно рассматривать как переходный этап от среднего к верхнему миоцену.

После проведенных исследований возникли вопросы с хронологической принадлежностью свит и толщ северной части Мишихинского разреза. Для подтверждения полученных данных было дополнительно изучено 7 образцов. Полученные данные представлены в таблицах (табл. 1, 2). Спорово-пыльцевые комплексы проб СП 3, СП 52 и D-2 по составу близки. В составе пыльцы голосеменных пород преобладают таксодиевые и секвойи, видовое разнообразие пыльцы хвойных пород отмечается лишь в пробе СП 52.

Табл. 1. Количество спор и пыльцы по дополнительным пробам северной Мишихи

[Table 1. The number of spores and pollen from additional samples Northern Mishikh]

\begin{tabular}{|c|c|c|}
\hline $\begin{array}{l}\text { Систематический состав } \\
\text { [Systematic composition] }\end{array}$ & $\begin{array}{c}2091 \\
\text { СП-49 }\end{array}$ & $\begin{array}{c}2091 \\
\mathrm{C} \Pi-10 \\
\end{array}$ \\
\hline 1 & 2 & 3 \\
\hline $\begin{array}{l}\text { Споры мхов и папоротников } \\
\text { [Spores of mosses and ferns] }\end{array}$ & 11.4 & 7.2 \\
\hline Riccia sp. & & 0.5 \\
\hline Coniopteris sp. & 0.5 & \\
\hline Selaginella sp. & 0.5 & \\
\hline $\begin{array}{l}\text { Sporites aff. durabilis (D-Hrebn.) } \\
\text { Kul. }\end{array}$ & 2.8 & \\
\hline $\begin{array}{l}\text { Polypodiaceae в том числе: } \\
\text { Laevigatosporites haardti ( R. Pot. } \\
\text { et Ven.) Th. et Pf. }\end{array}$ & 6.6 & 5.2 \\
\hline Lycopodiaceae & 0.5 & 0.5 \\
\hline Ophioglossum lineare (Kr.) Lubm. & & 0.5 \\
\hline Osmunda sp. & & 0.5 \\
\hline
\end{tabular}

Продолжение Табл. 1 [Continued Table 1]

\begin{tabular}{|c|c|c|}
\hline 1 & 2 & 3 \\
\hline Sphagnum regium Drozh. & 0.5 & \\
\hline Schagnum sp. & & 0.5 \\
\hline $\begin{array}{l}\text { Пыльца голосеменных } \\
\text { растений } \\
\text { [The pollen of gymnosperms] }\end{array}$ & 39.8 & 42.2 \\
\hline Tsuga .crispa Zakl. & 4.3 & 4.7 \\
\hline T. canadensis (L.) Corre & 2.4 & 3.3 \\
\hline T. acicularis Kupt. & 2.4 & 4.3 \\
\hline Picea sect. Eupicea & 2.4 & 4.4 \\
\hline Picea sect. Omorica & 2.4 & 1.2 \\
\hline Picea aff. tobolica Pan. & & 2.8 \\
\hline Picea sp. & & 0.4 \\
\hline Pinus s/g Haploxylon & 2.8 & 4.7 \\
\hline P. sect. Cembra & 3.7 & \\
\hline Pinus cembraeformis Zakl. & & 2.8 \\
\hline Pinus thunbergii Parl. & & 1.4 \\
\hline Pinus sect. Mirabilis & & 1.9 \\
\hline Taxodium distichiformis Zhezhel. & 7.1 & 2.8 \\
\hline Cupressaceae & 1.9 & \\
\hline Sequoia sempervirens Zherhel & 4.3 & 2.4 \\
\hline Sciadopitys tuberculata Zakl. & 1.4 & \\
\hline Keteleeria microreticulata Anan. & 0.9 & 1.4 \\
\hline Podocarpus gigantea Zakl. & & 2.3 \\
\hline P. spicatus R. Br. & & 0.4 \\
\hline Larix daurica Turcs. & 0.5 & \\
\hline Sparganium sp. & 3.3 & 1.0 \\
\hline $\begin{array}{l}\text { Пыльца покрытосеменных } \\
\text { древесных пород } \\
\text { [Pollen of angiosperms] }\end{array}$ & 46.9 & 47.1 \\
\hline Betulaepollenites sp. & 2.4 & 3.8 \\
\hline Carpinus perfectus Pan. & 1.9 & 1.9 \\
\hline Alnus pre-cordata Simps. & 2.8 & 2.9 \\
\hline Zelkova sp. & & 0.5 \\
\hline Planera herbidica Simps. & & 2.4 \\
\hline Ulmus crassa Pan. & 1.9 & 1.4 \\
\hline Myrica hartwegiformis Boitz. & & 2.8 \\
\hline Myrica sp. & 0.9 & \\
\hline Comptonia aborigena Gladk. & 0.9 & 4.3 \\
\hline Momipitis punctatus Nagy & 1.4 & \\
\hline Quercus williamsonia Trav. & & 1.4 \\
\hline Q. ovalis Pan. & 0.9 & \\
\hline Q. pokrovskajae Pan. & 1.8 & \\
\hline Fagus silvatica L. & 0.9 & \\
\hline F. parvifossilis Trav. & 0.9 & 1.4 \\
\hline Fagus sp. & 0.5 & 0.9 \\
\hline Juglans polyporata Vojc. & 3.5 & 6.7 \\
\hline J. jondonica Bolot. & 1.4 & \\
\hline $\begin{array}{l}\text { Engelhardtia quieta (R. Pot.) El- } \\
\text { sik. }\end{array}$ & 1.9 & 1.4 \\
\hline Platycarya strobilaceae S. et Z. & 0.6 & 0.5 \\
\hline Carya lacera Kor. & 5.7 & \\
\hline C. ordinaria Pan. & 1.4 & \\
\hline C. simplex Pan. & 2.4 & \\
\hline C. spackmania Trav. & & 5.2 \\
\hline Carya sp. & & 0.5 \\
\hline Pterocarya hupehensiformis Bolot. & 1.4 & 2.3 \\
\hline P. fraxinifolia (Lam.) Spach. & 0.9 & \\
\hline Cyclocarya cycloptera (Scht.) Iljinsk. & 1.4 & 1.1 \\
\hline Cyclocarya sp. & 0.9 & \\
\hline
\end{tabular}


Продолжение Табл. 1

[Continued Table 1]

\begin{tabular}{|l|c|c|}
\hline \multicolumn{1}{|c|}{1} & 2 & 3 \\
\hline Liquidambar brandonensis Trav. & 3.6 & 1.4 \\
\hline Liquidambar sp. & & 1.4 \\
\hline $\begin{array}{l}\text { Castanopsis pseudocingulum (R. } \\
\text { Pot.) Boitz. }\end{array}$ & 0.9 & \\
\hline $\begin{array}{l}\text { Castanopsis crenataeformis } \\
\text { Samig. }\end{array}$ & 0.5 & \\
\hline $\begin{array}{l}\text { Moraceae } \\
\text { Humulus sp. }\end{array}$ & & 0.9 \\
\hline Milfordia incerta (Th. et Pfl.) Kr. & & 0.5 \\
\hline Magnolia delicate Lubm. & & 0.5 \\
\hline $\begin{array}{l}\text { Corylopsis mtchedlishviliae } \\
\text { Lubm. }\end{array}$ & & 0.5 \\
\hline Triporopollenites robustus Pfl. & 2.8 & \\
\hline Salix caprea L. & 0.5 & \\
\hline Пыльца тpaв [Grass pollen] & $\mathbf{1 . 9}$ & $\mathbf{2 . 4}$ \\
\hline Ericaceae & 1.4 & 2.4 \\
\hline Onograceae & 0.5 & \\
\hline $\begin{array}{l}\text { Bceго cocчитано 3epeн } \\
\text { [Total number of grains counted] }\end{array}$ & $\mathbf{2 1 1}$ шт. & $\mathbf{2 1 0}$ шт. \\
\hline
\end{tabular}

Табл. 2. Количество спор и пыльцы по дополнительным пробам северной Мишихи

[Table 2. The number of spores and pollen from additional samples Northern Mishikh]

\begin{tabular}{|c|c|c|c|}
\hline $\begin{array}{l}\text { Систематический состав } \\
\text { [Systematic composition] }\end{array}$ & $\begin{array}{l}\text { Oбр. } \\
2091 \\
\text { СП-3 }\end{array}$ & $\begin{array}{l}\text { Oбр. } \\
2091 \\
\text { Д-2 }\end{array}$ & $\begin{array}{l}\text { Oбp. } \\
2091 \\
\text { СП } 52\end{array}$ \\
\hline 1 & 2 & 3 & \\
\hline Водные [Water] & 0.5 & & \\
\hline Planctonites & 0.5 & & \\
\hline $\begin{array}{l}\text { Споры мхов и папоротни- } \\
\text { ков [Spores of mosses and } \\
\text { ferns] }\end{array}$ & 5.9 & 5.9 & 34.1 \\
\hline Coniopteris sp. & & 0.8 & \\
\hline $\begin{array}{l}\text { Sporites aff. durabilis (D- } \\
\text { Hrebn.) Kul. }\end{array}$ & 0.5 & 0.4 & \\
\hline Polypodiaceae & 1.5 & 3.5 & 6.7 \\
\hline Lycopodiaceae & 1.4 & 0.4 & 2.9 \\
\hline Pteridaceae & 0.9 & & \\
\hline Osmunda sp. & & 0.8 & 0.5 \\
\hline S. regium Drozh. & 2.5 & & 1.0 \\
\hline $\begin{array}{l}\text { Пыльца голосеменных рас- } \\
\text { тений [The pollen of gymno- } \\
\text { sperms] }\end{array}$ & 13.8 & 24.1 & 34.1 \\
\hline Gikgo sp. & & 0.8 & \\
\hline Tsuga crispa Zakl. & & 0.4 & 3.8 \\
\hline T. canadensis (L.) Corre & 0.6 & & 1.0 \\
\hline Picea sect. Eupicea & & 1.4 & 3.0 \\
\hline Pinus s/g Haploxylon & 2.5 & 0.8 & 6.7 \\
\hline Pinus cristata Pan. & & 0.4 & \\
\hline Dacrydium sp. & & & 0.5 \\
\hline Taxodium distichum (L.) Rich. & 5.9 & 7.2 & 5.4 \\
\hline Taxodium sp. & & 0.8 & \\
\hline Cupressaceae & & & 1.4 \\
\hline $\begin{array}{l}\text { Sequoia semperviriformis } \\
\text { Zherhl }\end{array}$ & 3.9 & 5.2 & 3.0 \\
\hline Keteleeria sp. & & & 3.4 \\
\hline Podocarpus dacrydioides A. Rich. & & 0.8 & 1.0 \\
\hline P. libellus (R. Pot.) Lubm. & & & 1.0 \\
\hline
\end{tabular}

Продолжение Табл. 2

[Continued Table 2]

\begin{tabular}{|c|c|c|c|}
\hline 1 & 2 & 3 & 4 \\
\hline Podocarpus gigantea Zakl. & & & 2.0 \\
\hline Sciadopitys tuberculatus Zakl. & & & 1.9 \\
\hline Sparganium sp. & 0.9 & 6.3 & \\
\hline $\begin{array}{l}\text { Пыльца покрытосемен- } \\
\text { ных древесных пород } \\
\text { [Pollen of angiosperms] }\end{array}$ & 78.8 & 68.7 & 54.8 \\
\hline Betula sp. & 1.8 & 4.9 & 1.9 \\
\hline Carpinus granulatus Naryk. & 0.9 & & \\
\hline Carpinus sp. & 2.5 & 1.3 & 0.5 \\
\hline Alnus pre-cordata Simps. & 5.4 & 4.6 & 3.8 \\
\hline Zelkova sp. & 2.0 & 1.3 & 0.5 \\
\hline Planera herbidica Simps. & & 0.4 & \\
\hline Ulmus inaequaliarcuata Trav. & & 3.8 & \\
\hline Ulmus sp. & 2.5 & & \\
\hline Celtis parviporata Lubm. & & & 2.4 \\
\hline C.cheganica Lubm. & & & 1.9 \\
\hline Celtis sp. & 1.8 & & \\
\hline $\begin{array}{l}\text { Ulmoideipites planeraeformis } \\
\text { Anders. }\end{array}$ & 4.4 & 2.9 & 2.0 \\
\hline $\begin{array}{l}\text { Myrica pseudogranulata } \\
\text { Gladk. }\end{array}$ & 1.5 & & \\
\hline M. diversa Gladk. & 2.5 & & \\
\hline M. hartwegiformis Boits. & & 3.4 & 1.9 \\
\hline M. lubomirovae Gladk. & 3.9 & & \\
\hline Myrica sp. & 1.0 & & 0.5 \\
\hline Comptonia aborigena Gladk. & & 6.8 & \\
\hline C. podograria Gladk. & & & 2.0 \\
\hline C. compacta Gladk. & 0.9 & & \\
\hline Quercus gracilis Boitz. & & & 0.5 \\
\hline Q. aff. conferta Boitz. & 3.9 & 0.4 & 1.0 \\
\hline Q. williamsonia Trav. & & 1.7 & \\
\hline Fagus parvifossilis Trav. & & 1.6 & \\
\hline Fagus sp. & & 0.8 & \\
\hline Juglans sieboldianiformis Vojc. & & & 0.5 \\
\hline Juglans sibirica Vojc. & 5.9 & & 5.3 \\
\hline J. orbiculata Vojc. & 1.5 & & \\
\hline J. polyporata Vojc. & & 3.4 & 2.9 \\
\hline Platycarya plicata (R. Pot.) Elsik. & & & 0.5 \\
\hline Platycarya strobilaceae S. et. Z. & 0.9 & & \\
\hline $\begin{array}{l}\text { Platycaryapollenites irregula- } \\
\text { tus W. Kr. }\end{array}$ & 1.5 & & \\
\hline Carya punctata Mart. & 3.9 & 3.8 & 5.8 \\
\hline \multicolumn{4}{|l|}{ C. simplex (R. Pot et Ven.) Esik. } \\
\hline C. glabraeformis Boitz. & 4.4 & & 3.5 \\
\hline C. spackmania Trav. & & 2.1 & \\
\hline Carya sp. & 0.9 & & \\
\hline $\begin{array}{l}\text { Pterocarya hupehensiformis } \\
\text { Bolot. }\end{array}$ & 3.4 & 2.5 & \\
\hline Pterocarya sp. & 1.4 & & 4.8 \\
\hline Engelhardtia sp. & & 4.6 & \\
\hline $\begin{array}{l}\text { Cyclocarya cycloptera (Schl.) } \\
\text { Iljinsk. }\end{array}$ & 0.5 & 0.8 & \\
\hline Liquidambar brandonensis Trav. & & 0.8 & \\
\hline Liquidambar sp. & & & 1.0 \\
\hline Hamamelis scotica Simps & & 0.4 & \\
\hline Castanea vachrameevii Bolch. & & 1.7 & \\
\hline $\begin{array}{l}\text { Castanopsis crenataeformis } \\
\text { Samig. }\end{array}$ & & 0.4 & \\
\hline Castanopsis sp. & 0.9 & 0.8 & \\
\hline
\end{tabular}


Продолжение Табл. 2

[Continued Table 2]

\begin{tabular}{|c|c|c|c|}
\hline 1 & 2 & 3 & 4 \\
\hline Vitis sp. & & 1.7 & \\
\hline Magnolia aff. fenestrate Lubm. & & 0.4 & \\
\hline Magnolia sp. & 0.5 & 1.3 & \\
\hline Palmae & 2.5 & 1.7 & 1.9 \\
\hline Moraceae & 5.5 & 0.4 & 1.5 \\
\hline Humulus sp. & & 1.3 & \\
\hline Milfordia incerta (Th. et Pfl.) Kr. & 0.5 & 2.1 & \\
\hline Nyssa sp. & 1.4 & & \\
\hline $\begin{array}{l}\text { Corylopsis mtchedlichviliae } \\
\text { Lubm. }\end{array}$ & 1.5 & & \\
\hline C. crassa Lubm. & 0.4 & 0.4 & 1.0 \\
\hline C. princeps Lubm. & & & 0.5 \\
\hline Sabal turgaica Boitz. & & & 0.5 \\
\hline Ilex fimedia Th. et Pfl. & 0.5 & & \\
\hline Liquidambar brandonensis Trav. & & 0.8 & \\
\hline Liquidambar sp. & 0.5 & & 0.5 \\
\hline $\begin{array}{l}\text { Tilia pseudinstructa (Mai) I. } \\
\text { Kulk. }\end{array}$ & & 0.4 & \\
\hline Reevesiapollis sp. & 0.9 & & \\
\hline Sterculia sp. & 0.5 & 0.4 & \\
\hline Triatriopollenites plicatus Pfl. & 4.0 & 0.4 & \\
\hline Triporopollenites robustus Pfl. & 1.5 & 1.7 & \\
\hline Tricolporopollenites sp. & & & 2.4 \\
\hline $\begin{array}{l}\text { Tricolpopollenites liblarensis } \\
\text { (Thoms.) Pfl. }\end{array}$ & & & 1.0 \\
\hline $\begin{array}{l}\text { Reevesiapollis lubomirovae } \\
\text { (I. Kulk.) Lubm. }\end{array}$ & & & 0.5 \\
\hline $\begin{array}{l}\text { Trudopollis pompeckji (R. } \\
\text { Pot.) Lubm. }\end{array}$ & & & 2.0 \\
\hline Salix caprea L. & & 1.3 & \\
\hline Пыльца трав [Grass pollen] & 1.5 & $\mathbf{1 . 3}$ & \\
\hline Typhaceae & 0.5 & & \\
\hline Ericaceae & & 0.8 & \\
\hline Onagraceae & 1.0 & 0.5 & \\
\hline $\begin{array}{l}\text { Всего сосчитано зерен } \\
\text { [Total number of grains } \\
\text { counted] }\end{array}$ & $\begin{array}{l}203 \\
\text { ШIT. }\end{array}$ & $\begin{array}{l}237 \\
\text { шIт. }\end{array}$ & $\begin{array}{l}208 \\
\text { ШІт. }\end{array}$ \\
\hline
\end{tabular}

Богатый родовой и видовой состав пыльцы покрытосеменных древесных пород, а также наличие таких формальных родов как Triatriopollenites, Triporopollenites и вида Ulmoideipites planeraeformis позволяет коррелировать данную часть разреза с комплексами из отложений стратотипических разрезов, относящихся к переходным этапам нижнего и среднего эоцена.

Отличия в составе комплекса пробы СП 52 следующие: кроме разнообразия хвойных пород, где отмечено заметное участие пыльцы таких родов как: Keteleeria u Podocarpus, резко снижаются значения вида Ulmoideipites planeraeformis и начинает преобладать пыльца рода Juglans, что характерно для отложений верхнего эоцена-нижнего олигоцена.

Спектры проб СП 49 и СП 10 близки по составу, характеризуются примерно равным содержанием пыльцы голосеменных и покрытосеменных пород. Беднее становится состав пыльцы древесных растений и преобладает пыльца семейства Juglondaceae, где заметная роль отводится роду Carya. Наличие в спектре СП 10 заметного количества пыльцы рода Comptonia, может свидетельствовать о небольшой разнице в возрасте изучаемых отложений. Так отложения, опробованные пробами СП 10 и СП 49, накапливались в позднем олигоцене, но пачка отложений, где отобрана проба СП 10, формировалась немного раньше, чем осадки пробы СП 49.

Все вышеизложенное подтверждает, что отложения разреза северной части Мишихи формировались в эоцен-олигоцен-миоценовое время.

Палинологический материал для разреза скважины 545 в соответствии с вариациями состава комплексов объединил 4 палинозоны (рис. 3).

Главным признаком выделения I палинозоны является наличие в составе голосеменных пород пыльцы рода Podocarpus, а для покрытосеменных - рода Comptonia. Пыльца родов Cedrus и Sterculia вероятнее всего присутствовала в составе спектров уже в качестве реликтов. Пыльца данных родов исчезает на границе позднего олигоцена раннего миоцена. На основании вышеизложенного, отложения I палинозоны можно рассматривать как фрагмент последнего этапа олигоцена или раннего миоцена.

Во II палинозоне состав пыльцы покрытосеменных пород и его вариации позволил выделить две подзоны - $\mathbf{a}$ и b. В целом для палинозоны характерно возрастание доли участия в составе спектров пыльцы родов Magnolia, Engelhardtia, Carya, Pterocarya, Juglans, Quercus, Fagus, Momipites, Myrica, Carpinus. В составе голосеменных пород появляется пыльца рода Larix и пыльца семейства Taxodiaceae. Состав выделенных палинофлор позволяет рассматривать возраст отложений II палинозоны в объеме раннего миоцена. Подзона a выделяется на основе максимальных значений таких родов как: Carya, Pterocarya, Juglans, Myrica, Carpinus, а так же появления пыльцы рода Momipites и исчезновения пыльцы рода Comptonia в составе палинокомплексов. Кроме этого, в данной подзоне, отмечены пыльцевые зерна реликтов Liquidambar, Moraceae, Ilex, которые выше по разрезу не зафиксированы. Подзона b фиксируется появлением таких родов как: Quercus $u$ Magnolia, и семейства Taxodiaceae. Кроме этого отмечается возрастание количества пыльцы секции Picea sect. Eupicea и подрода Pinus s/g Diploxylon.

III палинозона характеризуетя доминированием пыльцы голосеменных растений, но в отличие от первых двух палинозон, здесь количество пыльцы родов Podocarpus, Tsuga, Keteleeria заметно уменьшается и исчезает в конце зоны. Главным показателем является пик содержания пыльцы родов Fagus u Quercus. Пыльца травянистых растений представлена разнотравьем, достигая максимального количества в разрезе. В составе спор отмечается максимум представителей семейств Polypodiaceae и Osmundaceae, но к концу зоны они практически исчезают из состава комплекса. Вышеописанный состав палинокомплексов хорошо коррелируется со спектрами стратотипических разрезов, как Западной Сибири, так и Восточно-Азиатского региона и характерен для начальных фаз среднего миоцена. 


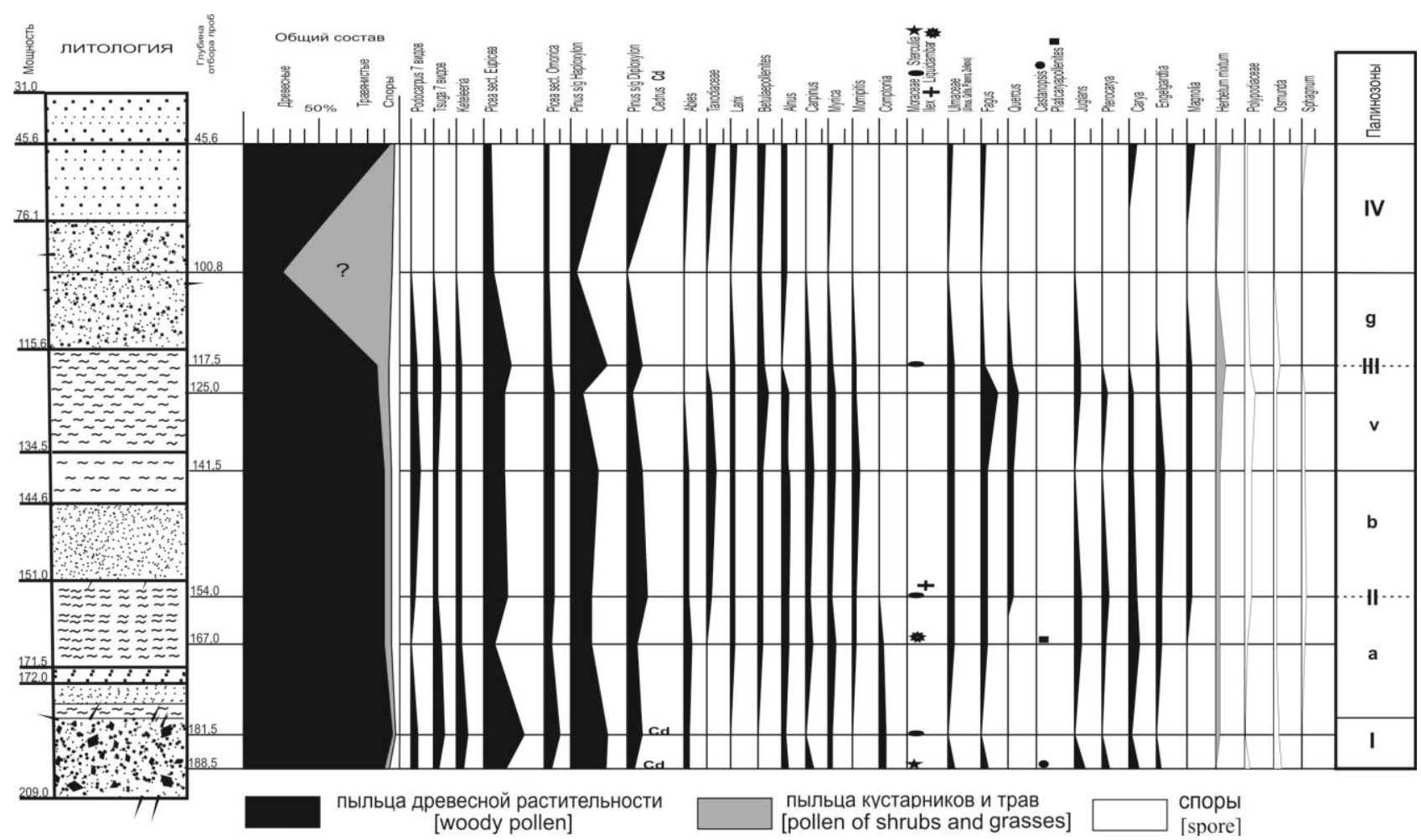

Рис. 3. Спорово-пыльцевая диаграмма разреза скважины 545.

[Fig. 3. Spore-pollen diagram of well section 545.]

В III палинозоне на основе изменения состава комплексов, выделено две подзоны $\mathbf{v}$ и $\mathbf{g}$. Подзона $\mathbf{v}$ выделяется по максимальным значениям таких родов как: Quercus, Fagus. Так же увеличивается количество пыльцы Alnus и Betulaepollenites. Снижаются значения пыльцы голосеменных пород, а именно Pinus.

Подзона $\mathbf{g}$ выделяется условно на основе резкой деградации группы покрытосеменных растений с постепенным выпадением из состава большого количества элементов. Роль пыльцы голосеменных возрастает в начале подзоны, с последующим уменьшением, до полного исчезновения следующих родов: Podocarpus, Tsuga, Keteleeria. Возможно, данный этап отразил заключительные фазы среднего миоцена.

IV палинозона выделена условно. Зона характеризуется резким сокращением значений пыльцы как голосеменных, так и покрытосеменных. Пыльца покрытосеменных пород представлена минимальным количеством. В виде единичных зерен отмечены представители родов: Mirica, Ulmacea, Fagus, Carya, Magnolia. Подобный состав палинокомплексов описан для позднего миоцена-раннего плиоцена в стратотипических разрезах прилегающих регионов $[1,2,3]$.

Результаты палинологических исследований при изучении разрезов обнажений 128 и 123 Восточного Саяна позволил, отобразить состав спорово-пыльцевых комплексов одной диаграммой, с выделением двух палинозон (рис. 4).

I палинозона характеризуется значительным преобладанием пыльцы голосеменных пород. В составе рода Tsuga определены три вида: Tsuga aff. Ignicula, T. diversifolia, T. canadensis. При этом следует отметить, что вид Tsuga acicularis характерен для отложений олигоцена территории Дальнего Востока. В небольшом количестве отмечена пыльца рода Podocarpus. Пыльца ели принадлежит двум видам Picea aff. alata и $P$. aff. media, первый из них относится к более древней секции Omorica, виды которой ведут свое начало с середины палеогенового периода.

В составе пыльцы рода Pinus доминируют представители секций Cembra, Strobus, Mirabilis. В небольшом количестве отмечена пыльца сосен секций, более молодых, в хронологическом отношении: Taeda, Banksia и Pitys. В небольшом количестве присутствует пыльца рода Abies и в виде единичных зерен отмечена пыльца Taxodium. sp. В составе пыльцы покрытосеменных пород преобладает семейство Juglandaceae. Здесь, доминируют виды следующих родов: Juglans, Pterocarya, Carya. Группа травянистой растительности представлена пыльцой одного семейства - Ericaceae. Споры в I палинозоне немногочисленны и слагаются представителями семейств: Polypodiaceae и Osmundaceae.

Описанный состав палинокомплексов обеспечивает надежную корреляцию возраста отложений разреза 128 в объеме нижнего миоцена неогеновой системы.

Для II палинозоны характерно возрастание роли, а также видового разнообразия рода Tsuga. Одновременно увеличивается количество пыльцы семейств: Fagaceae и Juglandaceae, где доминантой выступает пыльца родов: Quercus, Fagus, Juglans и Carya. На этом фоне отмечается возрастание видового разнообразия 

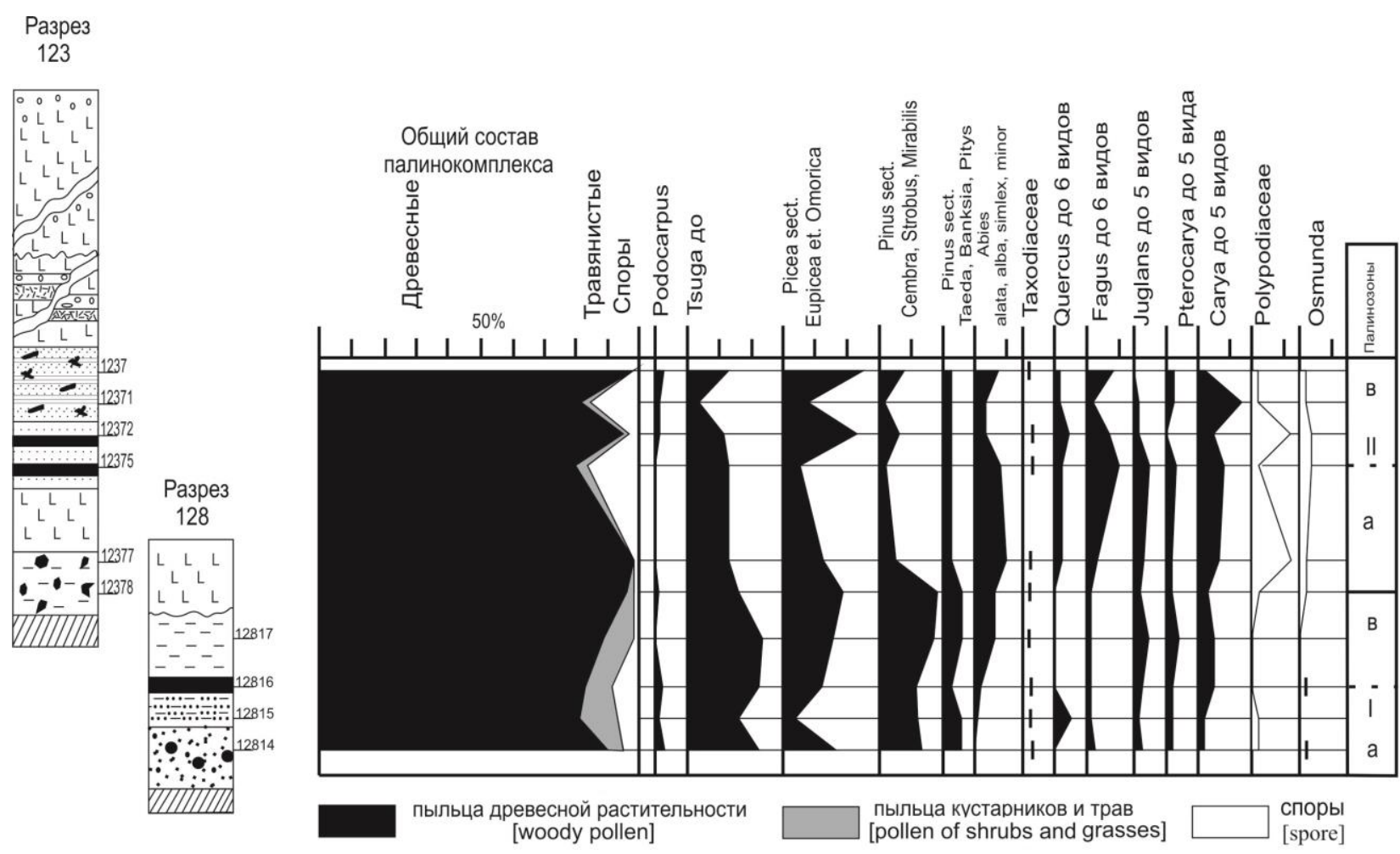

Рис. 4. Спорово-пыльцевая диаграмма для отложений разрезов 123, 128.

[Fig. 4. Spore-pollen diagram for deposits of sections 123, 128.]

пыльцы рода Carya. В небольшом количестве отмечены элементы характерные для отложений олигоцена (Cryptomeria japonica, Quercus williamsonia, Fagus japoniciformis), что позволяет соотносить время накопления отложений с поздними стадиями нижнего миоцена.

Пыльца трав в обоих разрезах малочисленна и встречена в отдельных образцах. Состав спор слагается в основном семействами: Polypodiaceae, Osmundaceae.

Для двух расчисток разреза обнажения 5029 были получены палинокомплексы, богатого как родового, так и видового состава. На спорово-пыльцевой диаграмме выделены три палинозоны (рис. 5). В общем составе преобладает пыльца голосеменных растений. Покрытосеменные древесные породы представлены богатым видовым разнообразием пыльцы семейств: Fagaceaе и Juglandaceae.

Для всех палинозон состав пыльцы голосеменных растений близок. Доминирует род Pinus и слагается пыльцой секций: Cembra, Strobus, Mirabilis. Характерным является большое количество пыльцы ели (секции Eupiceaе и Omorica). Заметную роль в составе комплексов играет пыльца рода Keteleeria, а также отмечено видовое разнообразие пыльцы рода Tsuga. В различном соотношении встречена пыльца следующих видов рода Tsuga: T. aff. acicularis, T. crispa, T. sieboldiiformis, T. Ignicula, T. aculeate, T. diversifolia. Такой богатый видовой состав данного рода отмечен для оптимальных фаз среднего миоцена ЮжноАзиатского региона.
В I палинозоне в составе пыльцы голосеменных пород отмечено присутствие единичных зерен таких элементов как: Pinus peuce, P. exinata, P. Protocembra, P. exelsaeformis, P. aff. Rutenica, P. strobiformis, Picea aff. Alata, P. schrenkianaeformis, P. aff media, а также Keteleeria aff.davidianaeformis, Podocarpus aff. Kazakhstanica, Abies mayriana, которые характерны для нижнего миоцена, а на данном этапе вероятно имеют статус реликтов. Вышеописанный состав палинокомплексов свидетельствует о формировании нижней части разреза в ранние фазы среднего миоцена.

Богатый видовой состав покрытосеменных древесных пород II и III палинозон указывает на формирование изучаемых отложений в течение оптимальных фаз среднего миоцена. Наглядно это доказывают изменения видового состава рода Carya, которые отражают хронологический переход от нижнего миоцена - Carya spackmania, C. Alba, C. grandipollina - к среднему - Carya elegans, C. jonanica и затем к верхнему миоцену - Carya oranica. B небольшом количестве, но практически по всему разрезу в составе комплексов отмечена пыльца таких родов как: Quercus, Fagus, Juglans, Pterocarya, Engelhardtia, Magnolia. Во второй и третьей палинозонах появляется заметное количество пыльцы семейства Ulmaceae (два рода Ulmus и Zelkova). Травянистые растения представлены практически только пыльцой семейства Ericaceae. Споры относятся к семействам: Polypodiaceae, Lycopodiaceae, Osmundaceae, Shpagnaceae. 


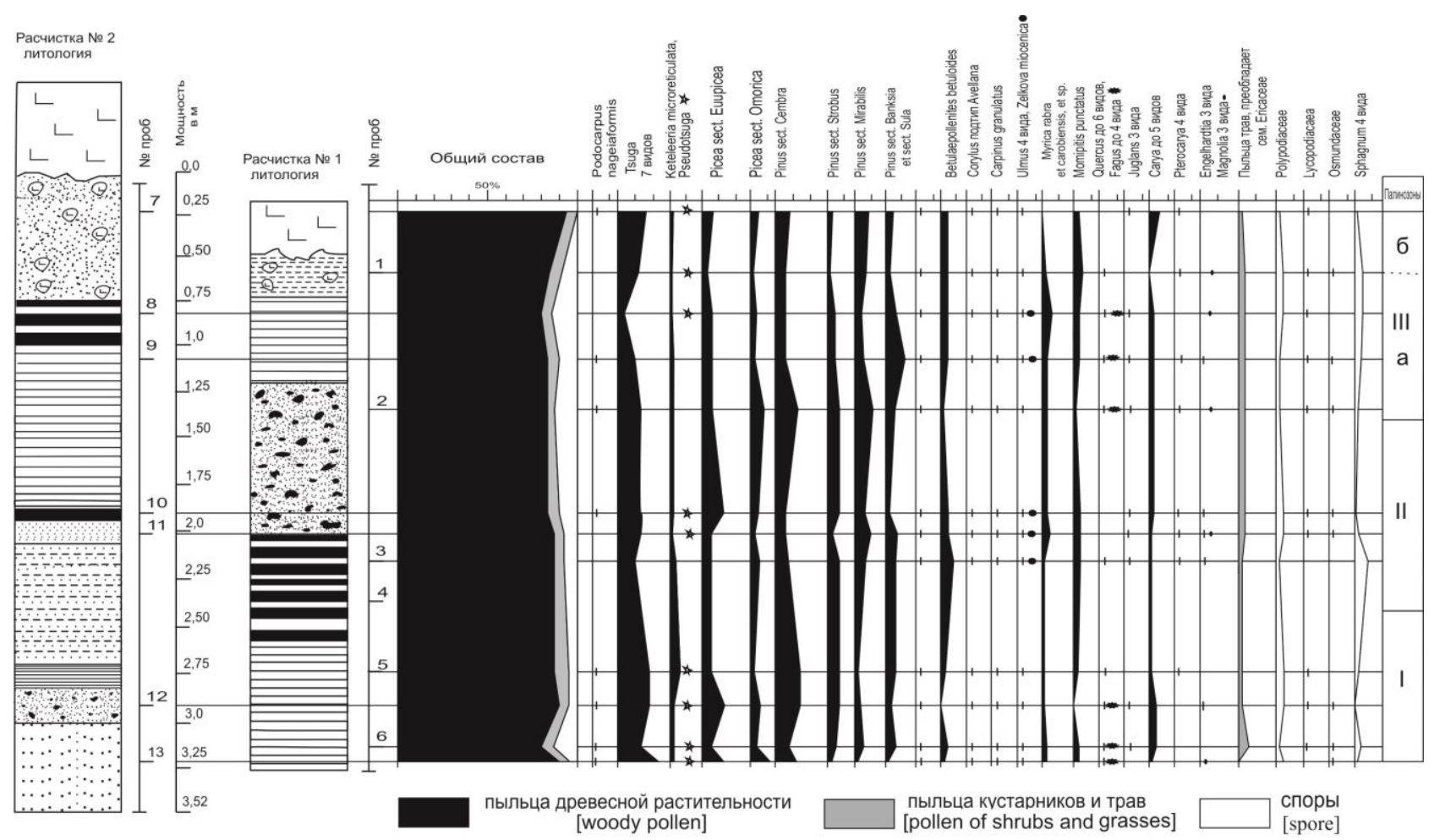

Рис. 5. Спорово-пыльцевая диаграмма для отложений разреза 5029.

[Fig. 5. Spore-pollen diagram for sediment in section 5029.]

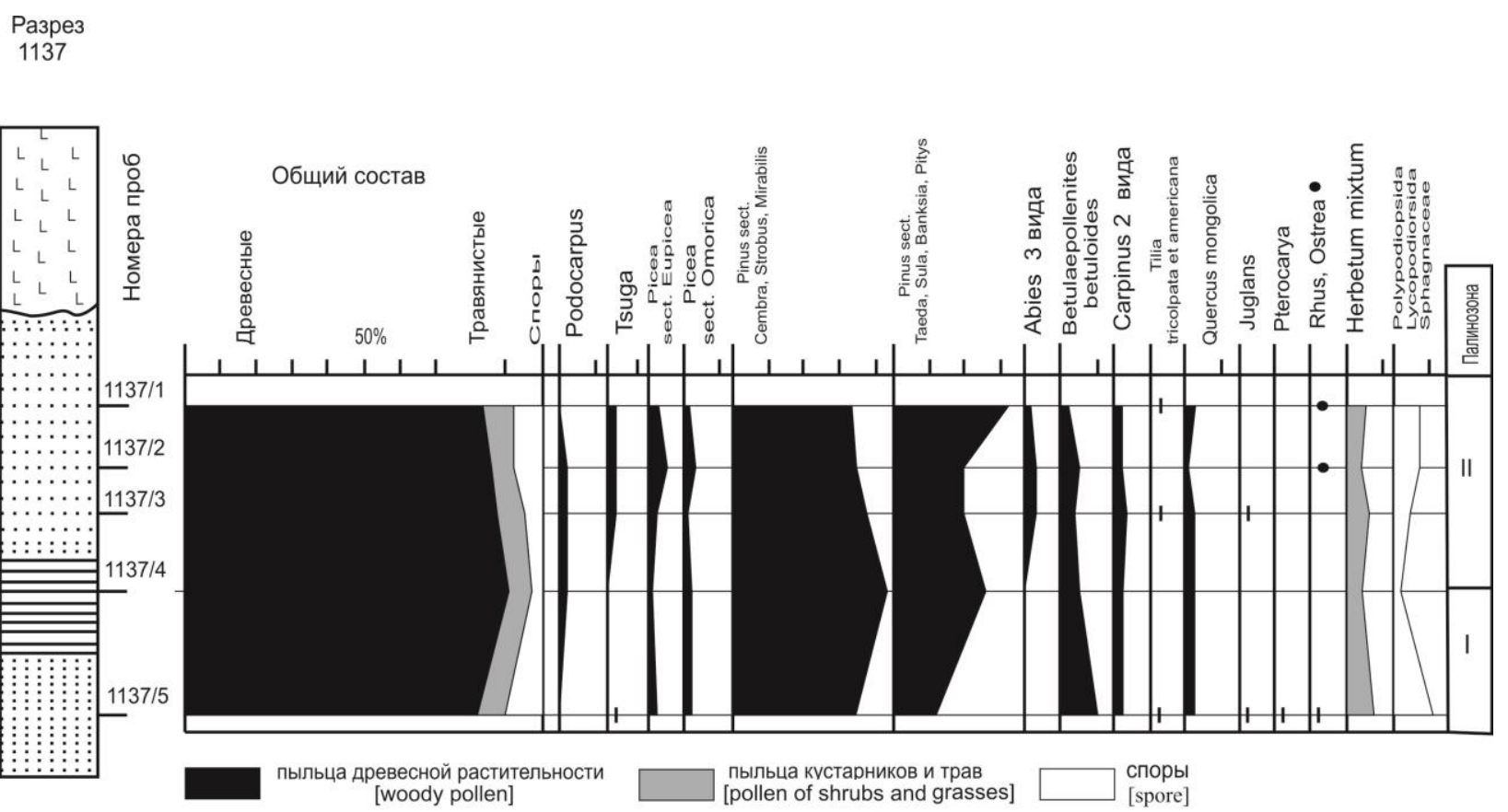

Рис. 6. Спорово-пыльцевая диаграмма для отложений разреза 1137.

[Fig. 6. Spore-pollen diagram for sediment in section 1137.]

Палинологические материалы, полученные по двум расчисткам разреза 5029, четко указывают на накопление осадочной толщи в ранние и оптимальные стадии среднего миоцена.

Для палинокомплексов разреза обнажения 1137, в целом характерно преобладание в составе пыльцы голосеменных представителей рода Pinus (рис. 6). Пыльца покрытосеменных древесных пород играет второстепенную роль и представлена семействами Betulaepollenites (родами Alnus и Betula), Carpinaceae (родом Carpinus), Fagaceae (родом Quercus).

Теплолюбивые элементы в своем большинстве 
характерны для плиоценовых отложений, но на этом фоне отмечена пыльца таких видов как: Quercus mongolica, Jglans jndonica, характерных для отложений верхнего миоцена, которые могли существовать в ранге реликтов.

В целом состав палинофлор данного этапа становится значительно беднее по сравнению с вышеописанными палинофлорами из разрезов 1281, 1237 , 5029. Возрастает разнообразие пыльцы травянистой растительности на уровне представителей семейств, что характерно для плиоцена. Описанный состав палинокомплексов свидетельствует о накоплении осадочной пачки отложений разреза 1137 в одну из стадий нижнего плиоцена.

\section{Выводы}

Детальный анализ состава палинокомплексов позволил впервые обозначить наличие на данной территории отложений палеогеновой системы и выстроить в хронологическом ряду спорово-пыльцевые комплексы неогена.

Для эоцен-олигоценовых отложений, представленных в разрезах южной и северной Мишихи, характерно практически одинаковое количество пыльцы, как покрытосеменных, так и голосеменных пород, максимальное значение в разрезах пыльцы родов Fagus, Myrica, и значительное участие пыльцы рода Carya, a также наличие единичных зерен реликтов Cryptomeria и Sciadopites и незначительное количество пыльцы, принадлежащей к искусственной классификации.

Последний этап олигоцена охарактеризован в нижней части скважины 545 и в начальных частях разрезов 123 и 128. Для отложений данного этапа характерно преобладание пыльцы голосеменных растений, среди которой ведущее значение имеют представители подрода Pinus s/g Haploxilon и секции Picea sect. Eupicea. Пыльца рода Tsuga, в течение накопления пачки отложений становится разнообразнее в видовом отношении. Так во II и III палинозонах скважины 545 зафиксировано до 7 видов данного рода. Кроме этого были встречены единичные зёрна пыльцы родов Cedrus и Sterculia, которые существовали в качестве реликтов.

Состав палинокомплексов из отложений разрезов 123 и 128 близок описанным комплексам из нижней части разреза 545 скважины. Различие заключается лишь в наличии в составе комплексов I палинозоны пыльцы рода Cedrus, что свидетельствует об отражении на спорово-пыльцевых диаграммах переходных фаз от олигоцена до первых стадий нижнего миоцена.

Отложения, миоценовый возраст которых обоснован палинологическими данными, представлен в разрезах скважины 545, обнажений 123 и северной и южной Мишихи.

Нижний миоцен, получил обоснование в разрезах северной, и южной Мишихи. Палинокомплексы характеризуются максимальным значением пыльцы таких видов как Magnolia, Engelhardia и Quercus, так же встречены единичные зёрна пыльцы семейств: Castanea, Abies, Ginkgo. В целом на данном этапе в разрезе характерно незначительное преобладание пыльцы покрытосеменных пород над голосеменными.

В разрезе скважиы 545 зафиксировано преобладание голосеменных пород над покрытосеменными. Кроме этого характерно наличие заметного количества пыльцы семейства Taxodiaceae и рода Abies. В составе покрытосеменных пород доминирует пыльца родов: Mirica, Carpinus, Carya и появляется пыльца родов Quercus и Magnolia.

Для палинокомлексов разреза обнажения 123 характерно примерно равное содержание пыльцы покрытосеменных и голосеменных пород. Среди покрытосеменных преобладает пыльца родов Quercus, Fagus и Carya. Наличие данных элементов может указывать на формирование данных отложений в поздние стадии нижнего миоцена-ранние стадии среднего миоцена

В целом для нижнего миоцена характерно преобладание пыльцы голосеменных пород. В отличие от олигоцена увеличивается количество пыльцы покрытосеменных растений, среди которых на ранних стадиях превалирует пыльца рода Carya, в поздние стадии возрастает роль пыльцы родов Quercus и Fagus. Среди голосеменных преобладает пыльца сосен подрода Haploxylon и ели секции Eupicea.

Средний миоцен определён в разрезах обнажений 5029, северной и южной Мишихи и скважины 545. Палинокомплексы разреза обнажения 5029 ярко демонстрируют оптимум среднего миоцена. Только нижняя часть разреза формировалась в ранние этапы среднего миоцена. Для отложений 545 скважины этого времени характерно снижение значений пыльцы голосеменных растений.

Для разрезов северной и южной Мишихи палинокомплексы данного этапа представлены примерно равным количеством пыльцы голосеменных и покрытосеменных. Количество пыльцы рода Carya уменьшается, но остаётся ведущей формой. В целом можно предположить, что отложения данного этапа являются завершающей фазой среднего миоцена или начальной фазой верхнего миоцена

Для среднего миоцена характерно преобладание пыльцы голосеменных со значительным участием пыльцы покрытосеменных растений. Среди голосеменных пород увеличивается количество пыльцы сосен подрода Diploxylon, а также богаче становится видовое разнообразие пыльцы родов Tsuga и Carya.

Отложения, отнесенные к плиоцену, получили обоснование палинологическими данными для разреза обнажения 1137.

В составе палинокомплексов преобладает пыльцы голосеменных пород, и заметная роль отведена пыльце травянистых растений. Среди голосеменных пород ведущее значение занимает пыльца сосен подрода Haploxylon, при заметном участии - подрода Diploxylon.

Таким образом, палинологические исследования позволили обосновать и уточнить хронологические рубежи выделенных свит и толщ в местной стратиграфической схеме для озерно-аллювиальной форма- 
ции, как для Восточных Саян, так и для южного побережья озера Байкал. Кроме этого на основе данных исследований были обоснованы стратиграфические рубежи базальтовых покровов тиссинской серии. Учитывая дискретность геологической летописи, материалы данной статьи отражают определенные стадии непрерывного изменения палинофлор неогена. Для получения последовательных изменений состава палинофлор работы данного направления следует продолжать с целью детализации стратиграфических рубежей кайнозоя Байкальской рифтовой зоны.

Конфликт интересов: Авторы декларируют отсутствие явных и потенциальных конфликтов интересов, связанных с публикацией настоящей статьи.

\section{ЛИТЕРАТУРА}

1. Болотникова М. Д. Спорово-пыльцевые комплексы третичных отложений западного побережья Японского моря. М.: «Наука». 1979. 194 с.

2. Томская А. И. Палинология Кайнозоя Якутии. М.: «Наука», Сибирское отделение. 1981. 220 с.

3. Фрадкина А. Ф. Палинофлоры неогена северо-востока Азии. М.: Наука.1983. 224 с.

4. Рассказов С. В., Лямина Н. А., Черняева Г. П., Лузина И. В., Руднева А.Ф., Резанов И. Н. Стратиграфия кайнозоя Витимского плоскогорья. Новосибирск: Академическое издво Гео. 2007. 193 с.

5. Скопинцев В. Г., Трегуб Т.Ф. Актуальные проблемы современной палинологии // Материаль XIV Всероссийской палинологической конференции, Москва, 5-8 июня 2017. С. 331-335.

\title{
PALEONTOLOGY, LITHOLOGY, STRATIGRAPHY
}

UDC 551.7.553.982.23.051

ISSN 1609-0691

DOI: https://doi.org/10.17308/geology.2020.1/2512

Received: 03.02.2020

Accepted: 20.02.2020

Published online: 25.03 .2020

\section{The evolution of the palinocomplexes for alluvial formation sediments of the Baikal Rift Zone in the Neogene}

\author{
(C2020 T. F.Tregub ${ }^{1}$, M. A.Volkov ${ }^{1 \bowtie}$, A. I. Hassan ${ }^{2,3}$, A. Al Hamoud ${ }^{3,4}$ \\ ${ }^{1}$ Voronezh State University, 1 Universitetskaya pl., Voronezh, 394018, Russian Federation \\ ${ }^{2}$ Irkutsk State University, 1 Karl Marks, Irkutsk, 664003, Russian Federation \\ ${ }^{3}$ Al-Baath University, Homs, Syria \\ ${ }^{4}$ Al-Furat University, Deir ez-Zor, Syria
}

\begin{abstract}
Introduction: Currently the issue of identifying stratigraphic units in sedimentary deposits of the Neogene Period in the territory of the Baikal Rift Zone is not completely resolved. To settle this issue we need to compare the results of palynological research of the sediments of the late Cenozoic of the Eastern Sayan and the southern coast of the Baikal Lake and systematize them within the chronological line of the Paleogene and the Neogene.

Methodology: All samples were processed in accordance with Grinchuk's separation method, which includes: treatment with $10 \%$ hydrochloric acid $(\mathrm{HCl})$, alkali $(\mathrm{NaOH})$, fluoric acid $(\mathrm{HF})$, and heavy liquid $\left(\mathrm{KJ}+\mathrm{CdJ}+\mathrm{H}_{2} \mathrm{O}\right)$. After enrichment the macerate can be seen under a microscope with $\mathrm{x} 400$-x600 magnification. The affiliation of spores and pollen to sections, genera, and species was determined by the attributes of the morphological structure of exine, intine, aperture apparatus, pores, and the presence of furrows.
\end{abstract}

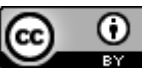

The content is available under Creative Commons Attribution 4.0 License.

\footnotetext{
${ }^{凶}$ Maksim A. Volkov, E-mail: 1994vomaan@mail.ru 
Results and discussion: The described palynological material of the deposits of lacustrine-alluvial formation of the southern coast of Baikal and sedimentary formations concealed under the basalts of the Tissa series in the territory of the Eastern Sayan was compared to the data from the stratotype sections of the neighbouring regions. This allowed us to substantiate the correspondence of the obtained data with the stratigraphic boundaries of the regional scheme of the Neogene. During the Eocene angiosperms prevailed in the general composition of pollen. The last stage of the Oligocene is characterized by the domination of gymnosperms, In the lower Miocene the pollen of gymnosperms prevailed as well, but in contrast to the Oligocene, the amount of angiosperm pollen increased. The wide variety of either angiosperm and gymnosperm pollen is typical for the middle Miocene. During the Pliocene the pollen of gymnosperms prevailed.

Conclusion: The detailed analysis of the composition of palynocomplexes allowed us for the first time to identify the presence of the Paleogene system deposits in this territory and to organize the spore-pollen complexes of the Neogene in chronological order. On the basis of the palynological research in the Baikal Rift Zone the chronological boundaries of the Tissa series were defined within the context of the Miocene and the lower Pliocene. The age limits of stages and suites of lacustrine-alluvial formation of the southern coast of Baikal within the boundaries of the upper Eocene and the lower Pliocene were also defined.

Keywords: Baikal Rift Zone, palynological complexes, stratigraphy, Neogene system.

For citation: Tregub T. F., Volkov M. A., Hassan A. I., Hamoud A. Al. The evolution of the palynocomplexes for alluvial formation deposits of the Baikal Rift Zone in the Neogene. Vestnik Voronezhskogo gosudarstvennogo universiteta. Seriya: Geologiya = Proceedings of Voronezh State University. Series: Geology, 2020, No. 1, pp. 39-50. DOI: https://doi.org/10.17308/geology.2020.1/2512

Funding: The study was supported by a grant from the Russian Foundation for Basic Research No.18-35-00417 mol_a.

Conflict of interests: The authors declare the absence of obvious and potential conflicts of interest related to the publication of this article.

\section{REFERENCES}

1. Bolotnikova M. D. Sporvo-pyl'tsevye kompleksy tretichnykh otlozhenii zapadnogo poberezh'ya Yaponskogo morya [Sporo- pollen complexes of the tertiary deposits of Western coast of the sea of Japan]. Moscow, Science publ, 1979, 194 p. (in Russ.)

2. Tomskaya A. I. Palinologiya Kainozoya Yakutii [Palynology the Cenozoic of Yakutia]. Moscow, Nauka publ., Siberian branch, 1981, 220 p. (in Russ.)

3. Fradkina A. F. Palinoflory neogena severo-vostoka Azii [Palynoflora of the Neogene of the North East Asia]. Moscow, Science publ, 1983, 224 p. (in Russ.)

4. Rasskazov S. V., Lyamina N. A., Chernyaeva G. P., Luzina I. V., Rudneva A. F., Rezanov I. N. Stratigrafiya kainozoya Vitimskogo ploskogor'ya [Stratigraphy of the Cenozoic of the Vitim plateau]. Novosibirsk: geo Academic publ., 2007, 193 p. (in Russ.)

5. Skopintsev V. G., Tregub T. F. Aktual'nye problemy sovremennoi palinologii [Actual problems of modern palynology] Materialy XIV Vserossiiskoi palinologicheskoi konferentsii [Proceedings of the XIV all-Russian palynological conference], Moscow, 5-8 June, 2017, pp. 331-335. (in Russ.)
Трегуб Тамара Федоровна - к. г. н., старший научный сотрудник, Воронежский государственный университет, Воронеж, Российская Федерация; E-mail: ttregub108@ yandex.ru; ORCID https://orcid.org/0000-0001-5814-1808

Волков Максим Андреевич - аспирант, инженер, Воронежский государственный университет, Воронеж, Российская Федерация; E-mail: 1994vomaan @ mail.ru; ORCID https://orcid.org/0000-0002-5342-8727

Хассан Абдулмонем Исса - аспирант, Иркутский государственный университет, Иркутск, Россия; ассистент, Университет Аль-Баас, Хомс, Сирия; Е-mail:

abdulmonemhassan86@gmail.com; ORCID

https://orcid.org/0000-0003-4919-4937

Аль Хамуд Аднан - аспирант, Иркутский государственный университет, Иркутск, Россия; ассистент, Университет АльФурат, Дейр Эз-Зор, Сирия; E-mail: hamoudadnan04@gmail.com; ORCID https://orcid.org/0000-0003-3648-699X

Авторы прочитали и одобрили окончательный вариант рукописи.
Tamara F. Tregub - PhD in Geography, senior researcher, Voronezh State University, Voronezh, Russian Federation;

E-mail: ttregub108@yandex.ru;

ORCID https://orcid.org/0000-0001-5814-1808

Maxim A. Volkov - postgraduate student, engineer, Voronezh

State University, Voronezh, Russian Federation;

E-mail: 1994vomaan@mail.ru;

ORCID https://orcid.org/0000-0002-5342-8727

Abdulmonem Issa Hassan - postgraduate student, Irkutsk State University, Irkutsk, Russia; Assistant, Al-Baath University, Homs, Syria; E-mail: abdulmonemhassan86@gmail.com; ORCID https://orcid.org/0000-0003-4919-4937

Adnan Al Hamoud - postgraduate student, Irkutsk State University, Irkutsk, Russia; Assistant, Al-Furat University, Deir ez-

Zor, Syria; E-mail: hamoudadnan04@ gmail.com;

ORCID https://orcid.org/0000-0003-3648-699X

All authors have read and approved the final manuscript. 